\title{
Detecting and Explaining the Sleeper Effect
}

\author{
DARLENE B. HANNAH \\ BRIAN STERNTHAL*
}

\begin{abstract}
The sleeper effect occurs when the persuasiveness of a message increases with the passage of time. Although the existence of the sleeper effect has been demonstrated in several recent investigations, the conditions necessary for its observation have not been specified. In the present research, a current view of memory operation is offered to predict the occurrence of the sleeper effect. This view is examined in two experiments. The findings are interpreted as being congenial with the memory explanation. The status of sleeper effect research is assessed in light of these findings.
\end{abstract}

\section{$\mathrm{T}$} he sleeper effect describes the phenomenon whereby the impact of a persuasive message increases with the passage of time. This effect is predicted on the basis of the dissociative cue hypothesis (Hovland, Lumsdaine, and Sheffield 1949). According to this hypothesis, the immediate persuasive impact of an otherwise compelling message is inhibited because of its association with a low credibility source or some other discounting cue. With the passage of time, however, the message becomes dissociated from the discounting cue, resulting in increased message influence.

The sleeper effect has intrigued researchers for more than 30 years. Inquiry was stimulated initially by the fact that the phenomenon repeatedly eluded demonstration (see Cook, Gruder, Hennigan, and Flay 1979). As these failures mounted, the sentiment grew for the belief that the sleeper effect did not exist (Gillig and Greenwald 1974). In the past several years, however, there have been several instances in which a sleeper effect has been observed. Thus the central research question is no longer whether a sleeper effect exists, but when it is likely to occur.

This issue is addressed in the present research. Our analysis begins with a summary of the empirical work pertaining to the sleeper effect. Because current theorizing is not adequate to account for the presence and absence of a sleeper effect, we introduce additional concepts to explain the phenomenon. Two experiments are reported to test our view. The results are discussed in terms of their relevance to marketing strategy and to future inquiry.

* Darlene B. Hannah is Assistant Professor of Psychology, Wheaton College, Wheaton, IL 60187. Brian Sternthal is Professor of Marketing, J. L. Kellogg Graduate School of Management, Northwestern University, Evanston, IL 60201 .

\section{SLEEPER EFFECT RESEARCH}

Attempts to demonstrate a sleeper effect suggest that it is obtained only in a limited set of circumstances. It is observed when a low-credibility source or other discounting cue is available to the message recipient after a message has been presented (Greenwald, Baumgardner, and Leippe 1979; Gruder et al. 1978). It is also found when the message source is not identified, but forewarning of the communication's persuasive intent causes discounting of the subsequent message (Watts and Holt 1979). In contrast, efforts to produce a sleeper effect have failed repeatedly when a low-credibility source is available as a discounting cue at the time of the message presentation (e.g., Capon and Hulbert 1973; Gillig and Greenwald 1974; Greenwald et al. 1979; Hennigan, Cook, and Gruder 1982).

Although these latter findings clearly contradict the dissociative cue hypothesis, they have not been considered as evidence for its falsification. Rather, the failure to demonstrate a sleeper effect has been attributed to inadequate operationalizations of theoretical constructs (Cook et al. 1979; Gruder et al. 1978). To remedy this problem, Cook and his colleagues identified four criteria useful in distinguishing between adequate and weak or faulty operationalizations of dissociative cue constructs:

1. A message with a strong initial impact on attitudes

2. A discounting cue that inhibits immediate attitude change

3. The dissociation of the discounting cue and message over time

4. The rapid dissociation of the discounting cue and message so that the message has some residual impact.

Evidence for the falsification of the dissociative cue hypothesis would emerge if a sleeper effect were not observed 
despite conformity to these criteria. No such evidence has been reported (see Gruder et al. 1978).

Thus it might seem reasonable to contend that the failure to demonstrate a reliable sleeper effect is due to faulty operationalizations of dissociative cue constructs. But this contention does not negate the possibility that the dissociative cue hypothesis provides an inadequate account of the sleeper effect. Quite the contrary, the recurrence of faulty dissociative cue hypothesis operationalizations in efforts to produce a sleeper effect may be symptomatic of a problem inherent in the theory. The problem is that the dissociative cue hypothesis is not adequate to explain the sleeper effect. It states that the association between a discounting cue and message is forgotten over time. Presumably some memorial process beyond the recency of information processing is involved in this dissociation, but the nature of this process is not explored. Without such a description, attempts to produce a sleeper effect are largely trial-and-error exercises. Cook's criteria can be invoked to detect inadequate operationalizations, but neither these criteria nor the dissociative cue hypothesis provide guidance in developing adequate construct operationalizations. Thus it appears that additional theorizing is needed to account for the process underlying the sleeper effect.

\section{THE AVAILABILITY-VALENCE HYPOTHESIS}

To address this concern, we introduce the availabilityvalence hypothesis. This hypothesis is based on currently held principles of memory operation (e.g., Anderson and Bower 1980; Tversky and Kahneman 1973). It has been shown to explain a variety of communication effects, including the impact of multiple requests on compliance (Tybout, Sternthal, and Calder 1983) and the persuasive effects of vividness manipulations (Kisielius and Sternthal 1984). The availability-valence hypothesis can be viewed as an extension to Greenwald's (1968) theory of cognitive response that offers a more detailed account of the role of information encoding in the judgment process than is proposed by the cognitive response view.

\section{Availability and Valence}

According to the availability-valence hypothesis, individuals' attitudinal judgments in response to a persuasive message are determined by the favorableness-or valence-of the issue-relevant information available in memory at the time of judgment. Because cognitive resources are limited, it is unlikely that all issue-relevant information will be available as a basis for attitudinal judgment (Calder, Insko, and Yandell 1974). Rather, information availability is thought to depend on its cognitive elaboration-that is, the number of related associations activated in storing a particular inference (Anderson and Bower 1980; Nisbett and Ross 1980). The greater the cognitive elaboration in processing information, the greater its availability in judgment.
Availability also depends on the recency of information processing. Memory appears to operate on a last-in-firstout principle such that more recently processed information is more available (Wyer and Carlston 1979). Simply stated, the contention is that individuals are active information processors whose attitudinal judgments are determined by how and when they process information.

The notion of availability is useful in predicting what information is likely to be used as a basis for judgment, but it is not sufficient for anticipating the direction of the attitudinal effect. For this purpose, the valence (favorableness) of available information must be known. Valence is defined in relative terms, in that one piece of information is viewed as being more or less favorable toward a message advocacy than some other information. Because memory capacity is limited, a change in attitude can occur when information currently held in memory is augmented or supplanted by information that is more or less favorable.

The availability-valence hypothesis provides a testable explanation of the sleeper effect. In this context, two pieces of information are potentially available: message information and discounting cue information. Further, it is assumed that associations to the message will be more favorable than associations to the discounting cue. This assumption seems reasonable, in that message information is selected with the intent to persuade, whereas a discounting cue is selected so as to undermine the influence of an appeal. The sleeper effect is expected when, with the passage of time, unfavorable associations evoked in response to the discounting cue are suppressed or supplanted by associations that are more favorable to the message advocacy.

One approach to testing this prediction entails designing a stimulus so that cognitive elaboration of the message information is greater than the elaboration of the discounting cue. When evaluation follows in close proximity to the stimulus presentation, the recency of processing unfavorable discounting cue information enhances its representation in recipients' attitudinal responses. Favorable associations to the message are also represented, but their number is constrained by the cognitive resource limitation noted earlier.

In effect, the availability of unfavorable discounting cue associations causes the favorableness of individuals' attitudes toward an advocacy to be suppressed. When evaluation is delayed, the greater cognitive elaboration of message information results in the greater availability of these associations in relation to the availability of discounting cue associations, which are neither elaborated nor recent. Attitudes thus become relatively favorable and a sleeper effect is observed.

\section{Relation to the Sleeper Effect Literature}

The explanation just outlined can account for the various outcomes reported in sleeper effect research. Specifically, the availability-valence hypothesis anticipates the 
observation of a sleeper effect when a discounting cue follows a message under the conditions established in prior studies. In these investigations, detailed and concrete communications were followed by terse presentations of the discounting cue. For example, Gruder et al. (1978) employed a 1,000-word message arguing against a fourday work week. Subjects were required to read this message twice and to underline the main point in each paragraph. In contrast, the discounting cues were brief phrases which labeled the message conclusion as false and which were designed to cause reactance (e.g., "any intelligent person has no choice but to believe" [the advocacy], $p$. 1068).

In effect, these stimuli make associations to the message information more available than associations to the discounting cue. But this disparity in thought availability is suppressed in the immediate attitude posttest because associations to the discounting cue are available by virtue of their recency of processing. Delaying the posttest, however, allows the greater elaboration of message information to be manifested in increased persuasion, so that a sleeper effect is observed.

The availability-valence hypothesis also anticipates the difficulty in obtaining a sleeper effect when the source or other discounting cue precedes the message. Here, the presentation of the message arguments may serve as retrieval cues that stimulate the reactivation of associations evoked earlier in response to the discounting cue. This is particularly likely if respondents readily associate the message and source. The reactivation of discounting cue associations enhances their cognitive elaboration and recency of processing. A sleeper effect is not observed because both discounting cue associations and message associations are likely to be available at the time of a delayed posttest.

In contrast, when the discounting cue follows an appeal, the message is not available as a retrieval cue to motivate elaboration of the discounting cue information. Thus with the passage of time, discounting cue associations become less available and attitude toward the message advocacy is enhanced. Consistent with this interpretation, Greenwald et al. (1979) observed a sleeper effect when identification of the low-credibility source followed the message, but not when this source preceded the appeal.

To observe a sleeper effect when the discounting cue precedes the message, a procedure is needed that does not cause the reactivation of discounting cue associations at the time of message processing. Forewarning an audience about the communication's persuasive intent, which Watts and Holt (1979) employed to produce a sleeper effect, appears to conform to this criterion. Perhaps this is because the forewarning cue is not specifically related to the various arguments advanced in the message. As a result, the message fails to stimulate elaboration of the forewarning cue. Over time, the forewarning cue becomes less available and a sleeper effect is observed. Presumably, other discounting cues-such as low-credibility sources-can also be found that minimize the reactivation of associations to the discounting cue when individuals are processing a subsequent communication.

The foregoing analysis indicates that the availabilityvalence hypothesis can accommodate the findings reported in sleeper effect research. However, this analysis does not provide a compelling basis for contending that the availability-valence hypothesis is superior to the dissociative cue hypothesis as an explanation for the sleeper effect; it may be possible to patch up the dissociative cue hypothesis so that it accommodates the outcomes of sleeper effect inquiry. Stronger evidence for the superiority of the availability-valence hypothesis would obtain if operationalizations implied by hypothesis-but not anticipated by the dissociative cue hypothesis-were successful in producing and eliminating a sleeper effect. This demonstration would be particularly impressive if a low-credibility source served as a discounting cue that preceded the message, because a sleeper effect has yet to be observed in such a context, and because this context is characteristic of those faced in applied settings.

In the present research, availability-valence notions serve as the basis for demonstrating sleeper effects. The context is one in which a low-credibility source precedes a persuasive message. Two experiments are reported. In Experiment I, the attempt to demonstrate a sleeper effect involves limiting the availability of unfavorable source associations in relation to the more favorable message associations, and varying recency of information presentation to manifest this disparity in thought availability. The purpose is to show that a sleeper effect can occur when the source is known at the time of message processing.

In Experiment II, the attempt to demonstrate a sleeper effect entails introducing a cue that enhances the availability of unfavorable source associations when stimulus information has been recently processed, and other more favorable associations when stimulus processing is less recent. As we shall discuss later, the observation of a sleeper effect in this situation is useful in assessing the relative explanatory power of the dissociative cue hypothesis and the availability-valence hypothesis.

\section{EXPERIMENT I}

The purpose of Experiment $I$ is to determine whether the availability-valence hypothesis is useful in designing a sleeper effect. Subjects received four contiguous messages, each preceded by a biographical description of the communicator. One of these messages-hereafter referred to as the stimulus message-was of particular interest in this study. The stimulus message was attributed to a lowcredibility source. After the four messages had been presented, subjects rated a subset of them that included the stimulus message on a series of attitudinal scales and other dependent measures.

Several strategies derived from the availability-valence hypothesis were employed to produce a sleeper effect. One strategy was designed to make message information 
more available than information about the source. Operationally, this entailed using two modalities to transmit the message and only one to describe its source. An auditory message accompanied by pictorial representations of the key message arguments was used to stimulate message associations. In contrast, only an auditory description of the source was presented so as to limit associations to the source. This strategy was chosen because pictorial and verbal (i.e., auditory) representations are thought to stimulate greater cognitive elaboration than verbal representations alone (Kieras 1978). The greater elaboration of message information was expected to make message associations more available than source associations, which were stimulated only by a verbal representation.

A second strategy was designed to limit the reactivation of information about the source during the message presentation. This was achieved by selecting a source who appeared to be a plausible spokesperson for the advocacy but not one who would come to mind spontaneously as a spokesperson for the issue. Thus subjects could not rely on associations they had previously stored that related message and source information. Rather, such an associative network would have to be established on the basis of stimulus information. The resources necessary for this purpose were unlikely to be available, given the demands of processing an externally paced pictorial and verbal message.

The third strategy employed to produce a sleeper effect involved affecting information availability by varying the recency of the information presentation. This entailed manipulating the position in which the stimulus message was presented and the position in which it was evaluated. Following this procedure, four delays between the stimulus message presentation and its evaluation were generated: no delay, two intermediate delays, and a long delay.

On the basis of the availability-valence hypothesis, it was expected that a sleeper effect would be observed by contrasting the attitudinal judgments induced in the nodelay and long-delay conditions. The number of favorable message associations was expected to be suppressed by the recency of processing information about the unfavorable source in the no-delay condition, but not after the long delay. Contrasts between the no-delay and intermediate-delay conditions were less likely to yield a sleeper effect because the intermediate delay would not be sufficient to inhibit the availability of information about the source. It should be noted, however, that support for these predictions depends upon empirical calibration of the delays. A sleeper effect is anticipated if the operationalization of no delay makes associations to the source available and the operationalization of long delay limits the availability of these associations.

Two additional dependent measures were administered to help specify the process underlying the treatment effects on attitudes. Subjects listed their associations to the message, following a variant of the cognitive response procedure developed by Greenwald (1968), and they were asked to recall as many of the message arguments as they could remember. If the availability-valence hypothesis is correct, subjects' associations to the message should be more favorable in the long-delay condition than in the no-delay condition. Moreover, the use of two modalities to present the message was expected to make it as memorable in the long-delay condition as it was in the nodelay condition. Observation of this latter outcome would reduce the likelihood that the demonstration of a sleeper effect was due simply to the order of stimulus presentation.

\section{Method}

Subjects. Sixty-four students recruited from introductory psychology courses participated in this study to fulfill part of a course requirement. The study was represented as an investigation dealing with the evaluation of television commercials and statements of public interest. Subjects participated in groups ranging from four to seven people. There were approximately equal numbers of males and females.

Procedure. Prior to participating in the main study, subjects were given two practice trials. The first practice trial involved an audio presentation of three messages, each attributed to a particular source. The second trial entailed viewing three television commercials. Subjects were told that they would evaluate two of the three messages in each trial, but the specific messages to be evaluated were not indicated. The message presented last was evaluated first in both trials. The other message evaluated was the first message presented in one trial and the second message presented in the other trial. The practice trials were represented as an opportunity for subjects to become familiar with the experimental procedures and the measuring scales. The evaluation of a subset of the messages was justified by noting that this procedure was similar to everyday experience in which people were not called upon to react to every message they saw or heard.

In actuality, the major purpose of the practice trials was to ensure that in the main study the availability of incoming information would reflect its recency of presentation. Achieving this goal required subjects to process each message as it was presented and to stop processing each message (except the last one) when it was over. It was hoped subjects would infer from their practice trial experience that it was useful to process all messages in the main study because any of them might be subject to evaluation. It also was hoped subjects would infer that it was judicious to think about the last message while awaiting the dependent variable administration because it was likely to be asked about first.'

The main study involved the presentation of four messages. Each was about 500 words in length, and each was attributed to a source described prior to the message. The sources and messages were tape-recorded for contiguous

\footnotetext{
' It was found in debriefing subjects that they made the inference anticipated.
} 
presentation to subjects. The source to which each message was attributed differed in credibility. This procedure limited subjects' ability to use some summary assertionsuch as all sources lacked credibility-to sustain the availability of source information. Rather, they were forced to learn the source of each message if they were to use this information in their later evaluation of the message advocacy.

The messages dealt with the law permitting a right turn on a red light, the recall of defective products, condominium conversion, and the election of judges. Four pictorial analogs of the main arguments proposed in each message were shown as the arguments were presented. As noted earlier, the pictorial representations were intended to increase the availability of message information in relation to information about the source.

The stimulus message dealt with the election of judges. Four arguments were advanced supporting the appointment of judges rather than their election. The description of the spokesman for this appeal, which served as the discounting cue, was presented just prior to the message. The spokesperson, named Mr. Roedder, was described as follows:

\begin{abstract}
Mr. Roedder owns and operates several apartment buildings. In operating this business, he has had several run-ins with the courts, where he has lost suits brought against him by tenants. He has been found guilty of rent gouging and violation of health and fire ordinances. To protect himself and other landlords, Mr. Roedder has organized an association to improve the court system. To date, he has had few other landlords join his association.
\end{abstract}

Subjects' reactions to the stimulus information was assessed in four ways. First, they indicated their associations to the stimulus message. A variant of Greenwald's (1968) cognitive response procedure was used for this purpose. Subjects were asked to list their associations pertaining to the message issue. Each association was recorded on a separate numbered line. Three minutes were given to complete this task. Subjects then categorized each association as favorable, neutral, or unfavorable to the message advocacy. This task was followed by a determination of subjects' attitudes toward the stimulus message on five seven-point bipolar adjective scales. These scales included good/bad, necessary/unnecessary, beneficial/not beneficial, appropriate/not appropriate, and worth maintaining/not worth maintaining. Next subjects were asked to recall as many of the arguments presented in the stimulus message as they could remember. Each argument recalled was listed on a separate line. Finally, the tape-recorded description of the spokesperson for the election of judges issue was played anew and subjects were asked to judge his expertise and trustworthiness on seven-point bipolar adjective scales (where 7 is the most unfavorable response). Subjects perceived the spokesperson to be somewhat inexpert $(\bar{X}=4.06)$ and untrustworthy $(\bar{X}=4.09)$.
The manipulation of the delay independent variable involved varying the order in which the stimulus message was presented and evaluated. For subjects randomly assigned to the no-delay condition, the election of judges message was presented last (i.e., fourth) and evaluated first. For those in the intermediate-delay conditions, the stimulus message was either presented second and evaluated first, or presented last and evaluated last (i.e., third). In this latter case, subjects responded to some questions pertaining to two of the other issues they had heard about before they responded to questions pertinent to the stimulus message. Finally, for subjects in the long-delay condition, the stimulus message was presented second and evaluated last.

\section{Results}

The means and standard deviations categorized by treatments are shown in the Table. Treatment effects on respondents' attitudes toward the stimulus message advocacy were examined first. Their responses were subjected to a principal-components factor analysis with varimax rotation. This analysis indicated that the five scales represented a single factor. Therefore, each subject's ratings on the five scales were summed to compose an attitude index. The Cronbach alpha statistic indicated that this scale was reliable $(\alpha=0.96)$.

The treatment effects on the attitude index were assessed using a one-way analysis of variance. This analysis indicated that the effect of delay was not significant $(F(3,60)=2.14, p=0.10)$. A series of contrasts was performed to assess the predictions of interest more closely. No differences were found between the no-delay condition and either of intermediate-delay conditions (message second: $t(60)=-1.49, p=0.14$; message last: $t(60)=-1.10, p=0.27)$. However, a sleeper effect was observed when the attitudinal responses in the no-delay and long-delay conditions were contrasted $(t(60)=2.51$, $p<0.01$ ).

To assess the mediation postulated by the availabilityvalence hypothesis, the effect of the treatments on subjects' cognitive responses was assessed. Following this hypothesis, it would seem appropriate to categorize subjects' associations on the basis of their stimulus origin. A precedent for such categorization has been established by Chaiken (1980), who classified associations that made explicit reference to the communicator as "source evoked," and ones in which this reference was absent as "message evoked." For example, the statement "he said REM sleep can be controlled" was classified as a source association, whereas the statement "reason for the trimester not sound logically" was classified as a message association.

Several problems militated against using Chaiken's categorization procedure in our research. One problem was the number of associations generated by our subjects that could be classified as source evoked. Chaiken em- 
TABLE

EXPERIMENT I: MEAN ATTITUDE, ASSOCIATIONS, AND RECALL CATEGORIZED BY DELAY CONDITION

\begin{tabular}{|c|c|c|c|c|}
\hline & \multirow[b]{2}{*}{$\begin{array}{l}\text { No } \\
\text { delay }\end{array}$} & \multicolumn{2}{|c|}{ Intermediate delay } & \multirow[b]{2}{*}{$\begin{array}{l}\text { Long } \\
\text { delay }\end{array}$} \\
\hline & & $\begin{array}{l}\text { Message } \\
\text { second }\end{array}$ & $\begin{array}{c}\text { Message } \\
\text { last }\end{array}$ & \\
\hline Attitudinal index ${ }^{\circ}$ & $\begin{array}{l}18.41 \\
(7.56)^{\circ}\end{array}$ & $\begin{array}{l}22.39 \\
(6.77)\end{array}$ & $\begin{array}{l}21.61 \\
(8.40)\end{array}$ & $\begin{array}{c}25.31 \\
(8.89)\end{array}$ \\
\hline Favorable associations & $\begin{array}{c}1.76 \\
(1.60)\end{array}$ & $\begin{array}{c}2.17 \\
(1.46)\end{array}$ & $\begin{array}{c}1.92 \\
(1.19)\end{array}$ & $\begin{array}{r}2.86 \\
(1.50)\end{array}$ \\
\hline Unfavorable associations & $\begin{array}{c}1.12 \\
(1.27)\end{array}$ & $\begin{array}{l}1.00 \\
(.70)\end{array}$ & $\begin{array}{c}1.15 \\
(1.46)\end{array}$ & $\begin{array}{l}.38 \\
(.50)\end{array}$ \\
\hline Net favorable associations & $\begin{array}{c}.65 \\
(2.89)\end{array}$ & $\begin{array}{c}1.17 \\
(2.01)\end{array}$ & $\begin{array}{c}.77 \\
(2.42)\end{array}$ & $\begin{array}{r}2.50 \\
(1.67)\end{array}$ \\
\hline Message recall & $\begin{array}{c}4.00 \\
(1.50)\end{array}$ & $\begin{array}{c}4.28 \\
(1.49)\end{array}$ & $\begin{array}{c}3.46 \\
(1.05)\end{array}$ & $\begin{array}{c}3.88 \\
(1.63)\end{array}$ \\
\hline Cell size & 17 & 18 & 13 & 16 \\
\hline
\end{tabular}

- Larger means reflect more favorable evaluations.

- Parentheses enclose standard deviations.

ployed a source induction in which the communicator delivered a lengthy statement that either praised or insulted the group to which subjects belonged. This presentation apparently was successful in stimulating a considerable number of associations that included an explicit reference to the source. In contrast, the source inductions used in our research were merely descriptive of the communicator and thus stimulated very few source associations.

Even if our subjects had generated a substantial number of source associations, Chaiken's categorization procedure would have been inappropriate. This is because her categorization rule is not adequate in identifying the origin of an association. Consider "reason for the trimester not sound logically." Chaiken categorized this statement as a message association, and it may indeed have been provoked by the message information. But if this were the case, it seems arbitrary to classify this statement as a source association if it happened to be preceded by the words, "the communicator's." Yet this classification is dictated by Chaiken's procedure.

In the face of the above problems, we attempted to develop an alternative classification procedure. This entailed having raters independently assess the cognitive responses by comparing them to the stimulus message and source information. Categorization based on the similarity between the stimulus information and the associations generated by subjects yielded highly discrepant interjudge classifications. This problem probably reflects the fact that memory is constructive. In generating cognitive responses, subjects relate stimulus information to their own knowledge repertoire. Thus the associations they record are idiosyncratic, and determining the origin of their associations is problematic.

Because an appropriate procedure for categorizing the origin of subjects' cognitive responses is not available, we resorted to a less direct measure of cognitive mediation. This entailed determining the favorableness of subjects' associations in response to the stimulus information. A net cognitive response score was calculated by subtracting the number of negative associations listed by each subject from the number of favorable associations. An analysis of variance indicated that the treatment effect on net cognitive responses was not significant $(F(3,60)=2.31$, $p=0.09$ ). Contrasts between the no-delay and the intermediate-delay conditions were also insignificant ( $t s$ $<1)$, but did reveal a sleeper effect $(t(60)=2.39, p$ $<0.05$ ). Similar conclusions emerge from an independent analysis of the favorable and unfavorable associations. There were more favorable associations in the long-delay than in the no-delay condition $(t(60)=2.18, p<0.05)$, and fewer unfavorable associations in the long-delay condition than in the no-delay condition $(t(60)=-1.96, p$ $<0.05$ ). All other contrasts for both favorable and unfavorable associations were not significant.

The effect of the treatments on recall of the message was also examined. An analysis of variance indicated that the number of message arguments recalled did not vary significantly by length of the posttest delay $(F<1)$. Contrasts between treatments were also nonsignificant ( $t s$ $<1)^{2}$

\section{Discussion}

In Experiment $\mathrm{I}$, it is demonstrated that persuasion can be enhanced with the passage of time when a lowcredibility source precedes the message. Attitudes toward the stimulus message advocacy were more favorable in the long-delay posttest than in the no-delay posttest. Moreover, subjects' associations were more favorable in the long-delay condition than they were in the no-delay condition.

These data are congenial to the availability-valence hypothesis. Interpreted from this perspective, attitudes toward the message advocacy are relatively unfavorable in the no-delay condition because the greater elaboration of favorable message associations is suppressed by the recency of processing source associations. With the passage of time, however, associations to the source become less available because they are no longer recent and not as greatly elaborated, and thus are supplanted by message

\footnotetext{
${ }^{2}$ Subjects' responses to the nonstimulus messages were also assessed. For one of these messages-the recall of defective products-subjects were highly favorable to the message position regardless of the order of its presentation or evaluation. The other nonstimulus message, which pertained to the law permitting right turns on red lights, was always presented first and evaluated second. Subjects' evaluations did not differ by experimental treatment $(F(3,60)=1.75, p=0.16)$.
} 
associations. Delayed attitude responses depend on associations to the message and therefore are more favorable toward the communication advocacy than evaluations that immediately follow the message. Moreover, the results of Experiment I cannot be explained adequately in terms of the effect of message presentation order on message recall. If this interpretation were viable, a treatment effect on recall should be observed, and no such effect is found.

An objection can be raised to our interpretation of the data in Experiment I. It is that the evidence offered for the availability-valence hypothesis is subject to rival explanation. Specifically, the variation of posttest delays may introduce threats to validity. One rival explanation for our data is that of local history. This potential artifact emerges because subjects in the no-delay condition were administered measures pertinent to the stimulus message first, whereas subjects in the long-delay condition completed other measures before the ones pertinent to the stimulus message. If this explanation were valid, one would also expect a significant difference in attitudes between the no-delay and intermediate-delay conditions, and no such outcome is observed.

Along the same line, it can be argued that subjects had more time to elaborate the message in the long-delay condition than in the no-delay condition and this difference is what caused the treatment effect. This explanation lacks plausibility because subjects were preoccupied with experimental tasks during the long delay that limited the extent to which they could engage in message elaboration. Moreover, if message elaboration had occurred, a significant treatment effect on recall is anticipated and no such effect is found.

Although the rival explanations for our interpretation of Experiment I do not seem highly plausible, they are sufficient to cast doubt on the reality of the sleeper effect. The demonstration of a sleeper effect would be more convincing if appropriate experimental controls were introduced. Moreover, this test should include the experimental manipulation of cognitive elaboration, which is a major construct postulated by the availability-valence hypothesis in explaining a sleeper effect. Experiment II was conducted with these issues in mind.

\section{EXPERIMENT II}

In Experiment II, an attempt is made to provide additional evidence for the availability-valence account of the sleeper effect. For this purpose, a procedure is needed that permits the manipulation of cognitive elaboration while holding constant the stimulus information pertaining to the message and source. Research reported by Tybout, Calder, and Sternthal (1981) is instructive in this regard. They demonstrated that the adverse effect of a rumor about a product could be eliminated by prompting subjects to elaborate favorable personal knowledge they had about the product just prior to its evaluation. In effect, attitudes were enhanced by introducing a retrieval cue that stimulated subjects to supplant unfavorable information related to the rumor with more favorable extracommunication information they had processed previously.

Applying this strategy to the present inquiry, a sleeper effect could be demonstrated if a retrieval cue were to stimulate more favorable associations with the passage of time. More specifically, the retrieval cue would have to be one that evoked unfavorable associations to the low-credibility message source when attitudes were assessed in close temporal proximity to the stimulus presentation, but more favorable extracommunication associations when the posttest was delayed.

This reasoning was made operational by exposing subjects to a series of messages, which included the stimulus message attributed to a low-credibility source. Respondents' attitudes were determined after either a short or a long delay. The retrieval cue was introduced in the questions subjects were required to answer just prior to the administration of the dependent measures. In the relevant cue condition, these questions pertained to the type of person who would support the stimulus message. It was anticipated that when the posttest delay was short, this cue would evoke associations to the low-credibility message source. These associations would be available because of their recent processing. In the long-delay condition, the retrieval cue was expected to evoke associations to some prototypical advocate for the stimulus message that respondents had previously stored in memory. In effect, the expectancy is that extracommunication associations would be relatively more available than associations to the low-credibility source as the processing of the latter information became relatively nonrecent. A sleeper effect is predicted because associations to the prototypical advocate were expected to be more favorable than those to the low-credibility source, who was described in a way so as to stimulate unfavorable associations.

Two additional treatments were included in the experimental design to limit plausible rival explanations for our data. Here, the questions asked just prior to administering the dependent variables were irrelevant to the stimulus message. Because this cue was irrelevant, it was not expected to interfere with the availability of associations evoked in response to the low-credibility source in either delay condition, therefore eliminating the sleeper effect. In effect, the irrelevant questions were intended to serve as an experimental control. They were expected to limit the generation of associations to a prototypical source, the process hypothesized to produce a sleeper effect when the questions are relevant.

Thus Experiment II involved a $2 \times 2$ factorial design in which posttest delay and relevance of retrieval cue were manipulated. The prediction is that a sleeper effect would be observed in the relevant cue conditions but not in the irrelevant cue conditions. To observe these outcomes requires careful calibration of the long posttest delay. This delay must be long enough to cause people to evoke pro- 
totypical associations in the relevant cue condition. Otherwise a sleeper effect would not be found. It must also be short enough to enable the evocation of associations to the low-credibility source in the irrelevant cue condition, or a sleeper effect would occur in this condition.

\section{Method}

Subjects. Thirty-six students from introductory psychology courses were recruited to participate in a study dealing with the evaluation of television commercials and other issues of public interest. Nine subjects were assigned randomly to each of the four conditions. They participated in groups of four or five. There were approximately equal numbers of males and females.

Procedure. The procedure employed in Experiment II is a variant of the one used in the previous study. Subjects were given two practice trials for the reasons noted in Experiment I. This was followed by five audiovisual messages, each preceded by an audio description of its source. Four of the messages were the same as those used in Experiment 1 . The fifth message dealt with the issue of mandatory retirement at age 65. Delay was manipulated by varying the positioning of the stimulus message (i.e., the election of judges). The stimulus message was the first message presented for those in the long-delay condition and was the third message presented for those in the short-delay condition.

The manipulation of posttest delay was intended to make unfavorable source associations available in both delay conditions, though somewhat less accessible in the long-delay condition. The choice of short delay was based on the finding reported in Experiment I that attitude was relatively unfavorable when the message was presented in the second position and evaluated first. This finding implies that the two messages interceding between the stimulus message and its evaluation are not sufficient to inhibit the availability of associations to the source. ${ }^{3}$ Therefore, this same two message delay was used to operationalize short delay in Experiment II.

The operationalization of long delay was based on a pilot test indicating that associations to the source would not be available if more than four messages interceded between the stimulus message presentation and its evaluation. This finding was accomodated by adding a fifth message in Experiment II. Long delay was achieved by presenting the stimulus message in the first position, fol-

\footnotetext{
${ }^{3}$ The intermediate delay condition, in which the stimulus message was presented fourth and evaluated last, also did not appear to inhibit the availability of source associations. This intermediate delay was deemed inappropriate in Experiment 11, where a retrieval cue was to be administered. The retrieval cue might seem contrived if it were presented prior to the stimulus-message dependent variables but after the dependent measures for non-stimulus messages. And the impact of the retrieval cue might have been lost if it were administered prior to the completion of all the dependent measures.
}

lowing it with four messages, and administering the dependent variables after the last message. ${ }^{4}$

Cognitive elaboration was varied by requiring subjects to answer several questions that were either relevant or irrelevant to the stimulus message. These questions were administered just prior to the evaluation of the stimulus message, and required subjects to describe the kinds of people that engage in particular behaviors and to speculate about people's motivation for doing so. ${ }^{5}$ In the relevant cue condition, these questions pertained to the stimulus message issue (the election of judges). In the irrelevant cue condition, the questions pertained to watching television commercials. After completing these questions, subjects were administered the same cognitive response, attitude, recall, and source evaluation dependent measures as were used in Experiment I. Responses on the source evaluation measures indicated that the spokesperson for the election of judges message lacked expertise $(\bar{X}=5.03)$ and trustworthiness $(\tilde{X}=5.17)$.

\section{Results}

A factor analysis of the five bipolar adjective scales indicated that three scales loaded on a single factor. These included good/bad, beneficial/not beneficial, and appropriate/not appropriate. Subjects' ratings on these items were summed to compose an attitude index. This index was highly reliable $(\alpha=0.91)$. The remaining two scales did not load on a factor and were dropped from the subsequent analysis. ${ }^{6}$

An analysis of variance indicated a significant delay $\times$ cue relevance interaction $(F=2.79, d f=1,32 ; p$ $=0.05)$, but no main effects $(F s<1)$. To specify further the nature of the interaction, tests of simple effects were performed. This analysis revealed a sleeper effect within the relevant cue conditions; attitudes toward the stimulus message were more favorable in the long-delay-relevantcue condition $(\bar{x}=16.22, S . D .=3.15)$ than in the shortdelay-relevant-cue condition $(\bar{x}=11.89, S . D .=4.07$;

\footnotetext{
4In Experiment I, we avoided presenting the stimulus message in the first position to minimize the chances of a primacy effect. Because it was found that the practice trials task minimized the likelihood of a primacy effect, the presentation of the stimulus message in the first position was used to operationalize long delay in Experiment II.

${ }^{3}$ In the relevant cue condition, subjects were asked the following questions:

How do you feel about people who try to change existing laws and policies?

What kind of people become involved in trying to change laws?

What do you think motivates people to take a stand against long established laws?

${ }^{6}$ Several procedural differences may account for the fact that the evaluation indices were not the same in Experiments I and II. Most prominent among these is the fact that in Experiment II a fifth message was included.
} 
$t(16)=2.30, p<0.05)$. Delay did not have a systematic effect on attitudes when the cue was irrelevant to the stimulus message (long delay $\bar{x}=11.56, S . D .=3.24$; short delay $\bar{x}=11.89, S . D .=5.18 ; t<1)$.

To assess the effect of treatments on individuals' associations postulated by the availability-valence hypothesis, the proportions of favorable associations generated in each treatment were examined. ${ }^{7}$ Consistent with availability-valence expectations, the proportion of associations. that were favorable to the stimulus message in the longdelay-relevant-cue condition (16 of 24 associations or 66.7 percent) was significantly greater than the proportion of associations that were favorable in the short-delayrelevant-cue condition ( 12 of 31 associations or 38.7 percent, $z=2.07 p<0.05$ ). There were no differences in the proportions of favorable associations between the long delay ( 8 of 24 associations or 33 percent) and the short delay ( 10 of 25 associations or 40 percent) in the irrelevant cue conditions $(z<1)$.

A further assessment of the mediation postulated by the availability-valence hypothesis involved an examination of subjects' responses to the relevant cue questions. If our theorizing is correct, associations to the message source would be available to subjects in the short-delayrelevant-cue condition. Because this source lacked credibility, these associations were expected to be unfavorable. By contrast, subjects in the long-delay condition were expected to rely on a more favorable prototypical source and thus generate more favorable associations.

Subjects' responses to each of the three relevant cue questions were coded by two judges. Disparities in coding were resolved by a third judge. The judges were instructed to code a response as positive if people who were involved in changing laws were described in a favorable light, as negative if such people were described in an unfavorable light, and as irrelevant if a subject's answer did not provide a characterization of the source.

Following this procedure, it was found that most subjects provided irrelevant responses to the question "How do you feel about people who try to change existing laws?" In responding to this question, subjects typically noted that their feelings depended on the law in question. More informative were subjects' responses to the questions pertaining to the kind of people involved in trying to change laws and their motivations for doing so. Using a chisquare test that incorporated Yates' correction for continuity, a significant treatment effect was found. Subjects in the short-delay condition were less favorable than those in the long-delay condition in responding about the kind of people who attempted to change existing laws $\left(\chi^{2}(1)\right.$

\footnotetext{
${ }^{7}$ The disparity in favorable and unfavorable associations was too small to detect treatment effects using the net cognitive responses score employed in Experiment I. This outcome may have been due to the addition of a fifth message or to the fact that several messages interceded between the stimulus message and the cognitive response measure in the short-delay condition. To overcome this problem, a proportion-ofassociations measure was employed in Experiment II.
}

$=3.98, p<0.05)$ and about their motivations for doing so $\left(\chi^{2}(1)=4.48, p<0.05\right)$. More specifically, subjects in the short delay tended to describe people as being selfserving, a characteristic that is descriptive of the message source. In the long delay, subjects dwelt on people's concern for their fellow man, which might be expected if subjects were considering a prototypical message advocate.

This analysis indicates that subjects' associations in response to the relevant cue were more favorable in the long-delay condition. Also of interest is whether these associations are related to subjects' attitudes toward the message issue. To address this concern, a median split was used to classify subjects as favorable or unfavorable in their responses to the relevant cue and attitudes toward the advocacy. The number of subjects who were favorable on both of the measures, unfavorable on both of the measures, and inconsistent in their responses was determined. Computation of a phi coefficient with Yates' correction for continuity indicated a marginally significant correlation ( $\phi=0.45, p=0.07)$, suggesting that individuals' responses to the relevant cue covaried with their attitude toward the issue.

Finally, the treatment effects on recall of the stimulus message were examined. Average recall in the short-delayrelevant-cue condition $(\bar{x}=2.0, S . D .=.75)$, short-delayirrelevant-cue condition $(\bar{x}=2.4, S . D .=.72)$, long-delayrelevant-cue condition $(\bar{x}=2.5, S . D .=1.6)$, and longdelay-irrelevant-cue condition $(\bar{x}=3.0, S . D .=1.1)$ did not differ significantly from each other $(F(1,31)=1.15$, $p=0.34){ }^{8}$ Thus availability of the message information was unaffected by delay.

\section{Discussion}

These results are consistent with the availability-valence predictions. As expected, attitudes toward the message advocacy became more favorable with the passage of time in the relevant cue conditions. This effect was obtained because the cue-which made available unfavorable associations to the source when the stimulus presentation was recent-evoked a greater proportion of favorable associations when the stimulus presentation was less recent. In the irrelevant cue conditions, the passage of time had no effect on attitudes, presumably because the irrelevant cue did not interfere with the availability of unfavorable source associations in either delay condition.

Thus Experiment II offers a clear demonstration that persuasion can increase over time and that the availabilityvalence hypothesis can account for this outcome. However, an objection may be raised to calling this demonstration a sleeper effect. According to this argument, the detection of a sleeper effect requires that a message that initially had limited effectiveness emerge as more effective at some later time. Because this does not appear to be

\footnotetext{
${ }^{8}$ The recall data for one subject were missing. Analysis was performed on the responses from the remaining 35 subjects.
} 
what is occurring in Experiment II, the contention is that the increase in persuasion found over time is not a sleeper effect.

This argument is based on faulty logic. The essence of the objection is that evidence for the existence of a sleeper effect is obtained only when increases in persuasion over time can be explained by the dissociative cue hypothesis. Failure of the theory to explain the effect observed is taken as evidence that the effect has not been demonstrated. A more logical view is that the failure of a theory to explain some effect is damaging to the theory. The fact that the dissociative cue hypothesis cannot account for the increase in persuasiveness over time observed in Experiment II does not compromise the fact that a sleeper effect has been detected. Rather, it underscores the inadequacy of the dissociative cue hypothesis.

\section{GENERAL DISCUSSION}

Several years ago, Gillig and Greenwald (1974) contended that it was time to lay the sleeper effect to rest. This view was based on the repeated failure to demonstrate its existence. Since that time, however, there have been several demonstrations of the effect. With the reporting of the present studies, a sleeper effect has been detected using a variety of discounting cues, and it has been detected whether the discounting cue precedes or follows a message.

Although this evidence is testimony to the existence of a sleeper effect, it does not necessarily imply that there should be a reawakening of interest in sleeper effect inquiry. Certainly it cannot be claimed that the sleeper effect is of interest because it offers an attractive and powerful instrument for persuasion. Its practical limitations are underscored by the elaborate set of interventions needed to demonstrate the phenomenon. Moreover, in relying on the sleeper effect to enhance influence, one runs the risk that the message and discounting cue will both be available or both be unavailable at the time message recipients are contemplating some action.

A more reliable strategy based on the availability-valence hypothesis would be to induce repeated exposure to a communication attributed to a highly credible source. Repeated message exposure is expected to stimulate the elaboration of message information as well as favorable associations to the source, and thus induce a favorable attitude toward the communication advocacy. Data reported by Johnson and Watkins (1971) is consistent with this prediction in that the persuasive effect of source credibility was shown to sustain over time when an appeal was presented several times.

Further pursuit of the sleeper effect would be justified if it were to advance understanding of the process by which people make attitudinal judgments. Sleeper effect studies conceived of as tests of the dissociative cue hypothesis are not promising in this regard. Indeed, more than 30 years of sleeper effect research has failed to enrich the explanation offered by the dissociative cue hypothesis.
The notions of discounting and dissociation have remained essentially unaltered, and these notions are not sufficient to explain extant sleeper effect outcomes. This lack of progress reflects inadequacies in the dissociative cue hypothesis. The problem with the hypothesis is that it does not provide a sufficiently detailed description of the process by which dissociation occurs, but characterizes the information processor as a passive recipient of information. Dissociation is interpreted to be a function of the recency of stimulus presentation. As Experiment II indicates, recency alone is not sufficient to account for a sleeper effect.

A more compelling account of the attitudinal judgment process is offered by the availability-valence hypothesis, which extends the dissociative cue hypothesis by invoking constructs beyond recency in accounting for attitudinal judgments. In so doing, the human organism is depicted as an active information processor. According to this view, attitudinal judgments depend on the valence of available associations at the time of judgment, and information availability depends, in turn, on the cognitive elaboration of information pertaining to a concept as well as on the recency of stimulus processing.

Sleeper effect studies provide a promising context in which to apply current understanding of the judgment process as described by the availability-valence hypothesis. As the present research illustrates, sleeper effect studies provide a context for examining cognitive elaboration and recency, two constructs posited by the availabilityvalence hypothesis to explain human judgment. The sleeper effect also is an appropriate vehicle for testing availability-valence notions because it facilitates a priori specification of information valence. The strategy employed in the present investigations was to detect the impact of information valence by selecting two stimuli that would evoke associations differing substantially in their valence. Specifically, in Experiment I the message was developed so that it provided compelling arguments for the position advocated, thus yielding positively valenced associations. In contrast, the discounting cue was a low-credibility source, who was described in a manner likely to evoke unfavorable associations. In Experiment II, the low-credibility source was chosen so that the associations evoked were likely to be less favorable than those generated in response to a prototypical advocate.

In sum, our analysis indicates that the availability-valence hypothesis offers a more adequate account of the judgment process than the dissociative cue hypothesis. The availability-valence hypothesis can explain the sleeper effect produced in our research and those found in the literature. Further testimony for the explanatory power of the hypothesis is reported in Experiment II, in which theoretically deduced operationalizations were used to eliminate the sleeper effect. Thus the availability-valence hypothesis provides a useful starting point from which communication strategy can proceed. Such strategies need not be confined to ones that rely on increased persuasion over time. Rather, the availability-valence hypothesis 
suggests that any procedure for stimulating the elaboration and recent processing of favorable information about an object will enhance persuasion.

\section{[Received April 1983. Revised April 1984.]}

\section{REFERENCES}

Anderson, John R. and Gordon H. Bower (1980), Human Associative Memory, Washington, D.C.: V. H. Winston.

Calder, Bobby J., Chester Insko, and Barry Yandell (1974), "The Relation of Cognitive and Memorial Processes to Persuasion in a Simulated Jury Trial," Journal of Applied Social Psychology, 4 (January/March), 62-93.

Capon, Noel and James Hulbert (1973), "The Sleeper EffectAn Awakening," Public Opinion Quarterly, 37 (Fall), 333358.

Chaiken, Shelly (1980), "Heuristic Versus Systematic Processing and the Use of Source Versus Message Cues in Persuasion," Journal of Personality and Social Psychology, 39 (November), 752-766.

Cook, Thomas D., Charles L. Gruder, Karen M. Hennigan, and Brian R. Flay (1979), "The History of the Sleeper Effect: Some Logical Pitfalls in Accepting the Null Hypothesis," Psychological Bulletin, 86 (July), 662-679.

Gillig, Paulette M. and Anthony G. Greenwald (1974), "Is it Time to Lay the Sleeper Effect to Rest?" Journal of Personality and Social Psychology, 29 (January), 132-139.

Greenwald, Anthony G. (1968), "Cognitive Learning, Cognitive Response to Persuasion, and Attitude Change," in Psychological Foundations of Attitudes, eds. Anthony G. Greenwald, Timothy C. Brock, and Thomas M. Ostrom, New York: Academic Press.

- Michael H. Baumgardner, and R. Leippe (1979), "In Search of Reliable Persuasion Effects: III. The Sleeper Effect is Dead. Long Live the Sleeper Effect!" unpublished manuscript, The Ohio State University.

Gruder, Charles L., Thomas D. Cook, Karen M. Hennigan, Brian R. Flay, Cynthia Alessis, and Jerome Halamaj (1978),
"Empirical Tests of the Absolute Sleeper Effect Predicted from the Discounting Cue Hypothesis," Journal of Personality and Social Psychology, 36 (October), 1061-1074.

Hennigan, Karen M., Thomas D. Cook, and Charles L. Gruder (1982), "Cognitive Tuning Set, Source Credibility, and the Temporal Persistence of Attitude Change," Journal of Personality and Social Psychology, 42 (March), 412-425.

Hovland, Carl H., Arthur A. Lumsdaine, and Fred D. Sheffield (1949), Experiments on Mass Communication, Princeton, $\mathrm{NJ}$ : Princeton University Press.

Johnson, Homer H. and Thomas A. Watkins (1971), "The Effects of Message Repetition on Immediate and Delayed Attitude Change," Psychonomic Science, 22 (2), 101-103.

Kieras, David (1978), "Beyond Pictures and Words: Alternative Information-Processing Models for Imagery Effects in Verbal Memory," Psychological Bulletin, 85 (May), 532-554.

Kisielius, Jolita and Brian Sternthal (1984), "Detecting and Explaining Vividness Effects in Attitudinal Judgments," Journal of Marketing Research, 21 (February), 54-64.

Nisbett, Richard and Lee Ross (1980), Human Inference: Strategies and Shortcomings in Social Judgment, Englewood Cliffs, NJ: Prentice-Hall.

Tversky, Amos and Donald Kahneman (1973), "Availability: A Heuristic for Judging Frequency and Probability," Cognitive Psychology, 5 (2), 207-232.

Tybout, Alice, Bobby J. Calder, and Brian Sternthal (1981), "Using Information Processing Theory to Design Marketing Strategies," Journal of Marketing Research, 18 (February), 73-79.

_ Brian Sternthal, and Bobby J. Calder (1983), "Information Availability as a Determinant of Multiple Request Effectiveness," Journal of Marketing Research, 20 (August), 280-290.

Watts, William A. and Lewis E. Holt (1979) "Persistence of Opinion Change Induced Under Conditions of Forewarning and Distraction," Journal of Personality and Social Psychology, 37 (May), 778-789.

Wyer, Robert S. and Donald E. Carlston (1979), Social Cognition, Inference and Attribution, Hillsdale, NJ: Laurence Erlbaum. 
Copyright of Journal of Consumer Research is the property of Journal of Consumer Research. Inc. and its content may not be copied or emailed to multiple sites or posted to a listserv without the copyright holder's express written permission. However, users may print, download, or email articles for individual use. 